\title{
Healthy Workplaces for Health Workers in Canada: Knowledge Transfer and Uptake in Policy and Practice
}

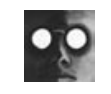

INVITED ESSAY

Judith Shamian, RN, PHD, LLD

President and CEO

VON Canada

Fadi El-Jardali, MPH, $\mathrm{PHD}$

Assistant Professor

Department of Health Management and Policy / Faculty of Health Sciences

American University of Beirut

$\infty$

ABSTRACT

The World Health Report launched the Health Workforce Decade (2006-2015), with high priority given for countries to develop effective workforce strategies including healthy workplaces for health workers. Evidence shows that healthy workplaces improve recruitment and retention, workers' health and well-being, quality of care and patient safety, organizational performance and societal outcomes. Over the past few years, healthy workplace issues in Canada have been on the agenda of many governments and employers.

The purpose of this paper is to provide a progress update, using different datacollection approaches, on knowledge transfer and uptake of research evidence in policy and practice, including the next steps for the healthy workplace agenda in Canada. The objectives of this paper are (1) to summarize the current healthy workplace 
initiatives that are currently under way in Canada; (2) to synthesize what has been done in reality to determine how far the healthy workplace agenda has progressed from the perspectives of research, policy and practice; and (3) to outline the next steps for moving forward with the healthy workplace agenda to achieve its ultimate objectives. Some of the key questions discussed in this paper are as follows: Has the existing evidence on the benefits of healthy workplaces resulted in policy change? If so, how and to what extent? Have the existing policy initiatives resulted in healthier workplaces for healthcare workers? Are there indications that healthcare workers, particularly at the front line, are experiencing better working conditions?

While there has been significant progress in bringing policy changes as a result of research evidence, our synthesis suggests that more work is needed to ensure that existing policy initiatives bring effective changes to the workplace. In this paper, we outline the next steps for research, policy and practice that are required to help the healthy workplace agenda achieve its ultimate objectives.

THE EARLY DECADES of the 21st century belong to health human resources (HHR). The World Health Report (World Health Organization [WHO] 2006) launched the Health Workforce Decade (2006-2015), with high priority given for countries to develop effective workforce strategies that include three core elements: improving recruitment, helping the existing workforce to perform better and slowing the rate at which workers leave the health workforce. In this recent report, retaining high-quality healthcare workers is discussed as a major strategic issue for healthcare systems and employers, and improving workplaces as a key strategy for achieving this goal.

The workplace can act as either a push or pull factor for HHR. Heavy workloads, excessive overtime, inflexible scheduling, safety hazards, poor management and few opportunities for leadership and professional development are among the push factors that result in poor recruitment and retention of HHR. Evidence shows that healthy workplaces improve recruitment and retention, workers' health and well-being, quality of care and patient safety, organizational performance and societal outcomes.
What are healthy workplaces? Based on existing definitions, there is not yet a standardized and comprehensive definition of healthy workplaces. In this paper, we define healthy workplaces as mechanisms, programs, policies, initiatives, actions and practices that are in place to provide the health workforce with physical, mental, psychosocial and organizational conditions that, in return, contribute to improved workers' health and well-being, quality of care and patient safety, organizational performance and societal outcomes (Griffin et al. 2006).

Over the past few years, healthy workplace issues in Canada have been on the agenda of many governments and stakeholder organizations. Nationally and internationally, robust evidence has been accumulated on the impact of healthy workplaces on workers' health and well-being, quality of care, patient safety, organizational performance and societal outcomes. This evidence has provided guidance for governments and employers in terms of what should be done to make the workplace healthier for healthcare workers. Across Canada, many initiatives to improve the working conditions for HHR are currently 
under way, but the continuing concerns suggest that barriers remain. An assessment of the progress to date is necessary in order to inform the next steps for research, policy and practice.

\section{Purpose}

The purpose of this paper is to provide a progress update on knowledge transfer and uptake in policy and practice, including the next steps for the healthy workplace agenda in Canada. Specifically, the objectives of this paper are (1) to summarize the current healthy workplace initiatives that are currently under way in Canada; (2) to synthesize what has been done in reality to determine how far the healthy workplace agenda has progressed from the perspectives of research, policy and practice; and (3) to outline the next steps for moving forward with the healthy workplace agenda to achieve its ultimate objectives.

\section{Approach}

The data-collection method undertaken for this paper includes the following:

- A review and synthesis of major reports and research documents on HHR in Canada published between 2000 and 2006

- A search of federal, provincial and territorial governments and key stakeholders' websites to identify relevant healthy workplace initiatives and plans

- A review of HHR action plans (released on December 2005) for the federal, provincial and territorial governments; more emphasis is given on the extent to which those plans incorporate healthy workplace issues, initiatives and targets

- A literature search of MEDLINE and the Cumulative Index to Nursing and Allied Health Literature (CINAHL)
(1995-2006) on the terms bealthy workplace, quality work environment and positive change in the workplace, including the terms healthcare professionals and nurses

This paper includes two main sections. In the first section, we review the progress that has been made on the healthy workplace issues in terms of research, policy and practice. Based on this review, we then outline (in the second section) the next steps for moving forward with the healthy workplace agenda.

\section{Progress}

\section{Progress in Research}

Over the past 20 years, the conceptual thinking about healthy workplaces has evolved at a progressive rate. From medical to ecological models, a better understanding has been provided of how a healthy workplace exerts its synergistic impacts on workers' health and well-being, patient outcomes, organizational performance and societal outcomes. Different conceptual models have blended a diverse range of perspectives and approaches by incorporating several factors addressed by different disciplines (Bachmann 2000; Dejoy and Southern 1993; Dejoy and Wilson 2003; Jones and Johnston 2000; Khoury et al. 1999; Laschinger and Kerr 2004; O’BrienPallas and Baumann 1992; Schaefer and Moos 1993; Shain 2000; Shain and Kramar 2004). Overall, the thinking behind the more comprehensive models is that multiple factors at all levels (extra-organizational, organizational and individual) are influential in creating healthy workplaces. Thus, no one level can be assessed without regard for the implications it may have on the others.

In terms of the progress at the empirical level, most of the research comes from 
nursing. More opportunities exist now than previously to translate this evidence to other types of health professionals. Robust evidence has accumulated (both at the national and international levels) on the benefits of healthy workplaces. Evidence shows that the consequences of healthy workplaces are not only individual (i.e., psychological, physiological and behavioural) and organizational outcomes (e.g., absenteeism, turnover and performance), but are also patient (i.e., quality of care and patient safety) and societal outcomes (i.e., impact on government programs and national healthcare costs) (Kelloway and Day 2005).

Research on the impact of the workplace on workers' health and well-being shows that job stress increases the risk of musculoskeletal injuries, accidents, physical and mental illness, substance abuse and smoking. Hospitals with fluctuating staff levels were found to have a higher rate of needle-stick injuries than did magnet hospitals - institutions where staffing is stable. Excessive workloads were associated with negative physical and mental health outcomes among general nurses (Tyler and Cushway 1992).

The relationship between healthy workplaces and quality of care and patient safety has been demonstrated in numerous studies (Griffin et al. 2006). Evidence shows that an increased workload leads to an increased likelihood of errors involving patients (Sexton et al. 2000). Robust evidence exists on the inverse relationship between nurse staffing and adverse events among patients (Lee et al. 1999; van Servellen and Schultz 1999). Needleman et al. (2001) found strong evidence of an association between patient outcomes and the share of total staffing by registered nurses (RNs). Higher $\mathrm{RN}$ staffing was associated with a $3-12 \%$ reduction in the rates of patient outcomes potentially sensitive to nursing. Numerous studies in Canada have found that high nurse-to-patient ratios lead to complications such as higher infection rates and poorer patient outcomes. Additionally, a study by Tourangeau et al. (2006) found that a $10 \%$ increase in the percentage of $\mathrm{RNs}$ in the staff mix is associated with six fewer deaths for every 1,000 discharged patients. The same study found that a $10 \%$ increase in nurse-reported adequacy of staffing and other resources is associated with 17 fewer deaths for every 1,000 discharged patients.

In terms of the impact of healthy workplaces on organizational performance, research shows that promoting healthier workplaces motivates health workers, enhances morale, reduces absenteeism, reduces personnel and welfare problems, leads to better outcomes and increased overall efficiency and improves organizational performance, competitiveness and public image (Chu et al. 2000; Kramer and Cole 2003; Price and Mueller 1981; Whitehead 2006). An increasing body of evidence suggests that poor workplaces result in a substantial health burden and cost that health service organizations bear as a result of ill health among their staff. The consequences for any organization that has an unhealthy workforce are many and include work-related accidents, high rates of absenteeism, a high turnover, high levels of stress, loss of productivity and a high incidence of health-related litigation (Addley et al. 2001; Verow and Hargreaves 2000; Whitehead 2006).

In relation to societal outcomes, evidence shows that consequences of healthy workplaces involve not only workers' health and well-being and organizational outcomes, but also societal outcomes (i.e., national healthcare costs and economy) (Kelloway and Day 2005; Lowe 2003). In the United States alone, the most accurate 
estimates show that deaths from job-related injuries, nonfatal injuries, deaths from disease and illnesses amounted to US\$65 billion in direct costs and US $\$ 106$ billion in indirect costs in 1992 (Lowe 2003). In Australia, estimates of the direct costs of workers' compensation are $1.5 \%$ of the gross national product and about $20 \%$ of total healthcare costs (Chu et al. 2000). In Canada, it is estimated that work-life conflicts cost the healthcare system approximately $\$ 425.8$ million in physician visits in 1996-1997 (Duxbury et al. 1999). Ennals (2002) emphasized that organizations are obliged to consider the world beyond the workplace - the one where workers are engaged as citizens. Subsequently, and in line with the public health commitments of health service organizations, the healthy workplace potentially influences the health of immediate employees and their wider social circle (Whitehead 2006). While the impact of healthy workplaces on societal outcomes is less robust (and still awaits further systematic research), our review of the existing evidence shows that horrific economic and social costs are being incurred as a result of unhealthy workplaces in healthcare organizations.

Overall, as a result of more than 20 years of research, there is increasing evidence of the benefit of healthy workplaces on workers' health and well-being, patient outcomes, organizational performance and societal outcomes. Given this evidence, one would ask, has the existing evidence on the benefits of healthy workplaces resulted in policy change? If so, how and to what extent? Across Canada, many policy initiatives have been undertaken to create healthy workplaces for healthcare workers. Below, we provide a summary of those key healthy workplace initiatives.

\section{Progress in Policy}

Has the existing evidence on the benefits of healthy workplaces resulted in policy change? The answer to this question would help inform the debate about what can be done as next steps (i.e., to increase the chances that evidence will bring further changes to policy domains).

Despite the availability of a large body of knowledge on healthy workplaces for the past 20 years, it took the leadership of the Office of Nursing Policy at Health Canada in 2000 to engage policy-makers, researchers and service communities, including unions, executives and decision makers, to get the issue onto the policy agenda. This initiative led to much of the work that is described in this paper. Today, many policy initiatives to improve the workplace for healthcare workers are currently under way across Canada. Before summarizing and providing an update on those initiatives, it would be important to outline briefly the key national reports that contributed significantly to developing those policy initiatives on healthy workplaces. These reports are listed below:

- Canadian Health Services Research Foundation (CHSRF) (2001): "Commitment and Care: The Benefits of a Healthy Workplace for Nurses, Their Patients, and the System." This report provided a significant set of recommendations to improve working conditions and strengthen nursing across Canada.

- Canadian Nursing Advisory Committee (CNAC) (2002): Our Health, Our Future: Creating Healthy Workplaces for Canadian Nurses. Fiftyone recommendations were provided by this report that offered governments, employers, unions and other stake- 
holders a broad menu of helpful suggestions to improving the working conditions of Canada's nurses.

- Standing Senate Committee on Social Affairs, Science and Technology (2002): The Health of Canadians - The Federal Role. In October 2002, this report, known as the Kirby Report, recommended that the federal government work with other concerned parties to create a permanent national coordinating body for HHR, composed of representatives from key stakeholder groups and the different levels of government. One of its mandates is to share and promote best practices with regard to strategies for retaining skilled healthcare professionals and coordinating efforts to repatriate Canadian healthcare professionals who have emigrated to other countries.

- Commission on the Future of Health Care in Canada (2002): Building on Values: The Future of Health Care in Canada. On November 28, 2002, the commission delivered its final report (known as the Romanow Report) to Canadians. The report was concerned about the quality of working life, especially for nurses, and the impact of poor working conditions on nurses' health and quality of patient care. In this report, it was recommended that the Health Council of Canada should collect, analyze and regularly report on relevant and necessary information about the Canadian health workforce, including critical issues related to recruitment, distribution and remuneration of healthcare providers.

The above reports contributed significantly to the federal, provincial and territorial policies and programs. For instance, the
HHR component that was incorporated into the federal, provincial and territorial health accord of 2003 included a specific focus on recruitment and retention and healthy workplaces (Health Canada 2003). In a three-year period (2000-2003), researchers strived to bring the problem of low-quality work environments for nurses to the attention of governments. Efforts focused on providing new knowledge and raising awareness and dissemination.

As a result of tremendous efforts, the move toward healthy workplaces has been expanded to benefit not only Canada's nursing workforce but other healthcare workers as well. The 2003 and 2004 First Ministers' Accords on Health Care Renewal identify revitalization strategies for Canada's health system workforce. Coordinated actions to improve recruitment and retention are needed. The centrepiece of retention strategies is a healthy workplace initiative for healthcare workers. Workplace health issues now appear on public and government HHR policy agendas, on the Health Council of Canada agenda and in reviews conducted by provinces and territories. In addition, and in part of the commitments made to reform the health workforce, Canada's federal, provincial and territorial governments agreed to report to the public on their action plans by December 31, 2005, including targets for training, recruitment and retention and healthy workplaces for health professionals.

\section{Key Initiatives and Progress Update}

This section summarizes current policy initiatives undertaken (2001-2006) at the national and provincial levels by governments and stakeholder organizations. Table 1 provides a detailed description of those initiatives. 
Table 1. Summary of key initiatives

\begin{tabular}{|c|c|}
\hline Initiative & Accomplishments \\
\hline $\begin{array}{l}\text { 1. Work-life quality indicators (Canadian Council on } \\
\text { Health Services Accreditation) }\end{array}$ & $\begin{array}{l}\text { New workplace quality indicators have been developed by the } \\
\text { council and are now being tested. }\end{array}$ \\
\hline $\begin{array}{l}\text { 2. Healthy Work Environments Best Practice Guidelines } \\
\text { (Registered Nurses' Association of Ontario) }\end{array}$ & $\begin{array}{l}\text { The project delivers six guidelines for the following topics: (1) } \\
\text { developing and sustaining nursing leadership; (2) developing } \\
\text { and sustaining effective staffing and workload practices; (3) } \\
\text { embracing cultural diversity in healthcare: developing cultural } \\
\text { competence; (4) professionalism of the nurse; (5) collaborative } \\
\text { practice among nursing teams; and (6) workplace health, } \\
\text { safety and well-being of the nurse. }\end{array}$ \\
\hline $\begin{array}{l}\text { 3. Survey of the Work and Health of Nurses (Canadian } \\
\text { Institute for Health Information) }\end{array}$ & $\begin{array}{l}\text { The questionnaire content has been finalized, pilot tested and } \\
\text { implemented. Survey results were released in December } 2006 \text {. }\end{array}$ \\
\hline 4. Nursing Sector Study Corporation & $\begin{array}{l}\text { Phase I has been completed.* Phase II will build on the } \\
\text { findings and recommendations of the phase I report to help } \\
\text { develop a pan-Canadian nursing human resources strategy. }\end{array}$ \\
\hline 5. Health Canada's Healthy Workplace Initiative (HWI) & $\begin{array}{l}\text { Health Canada provided targeted funding to support } \\
\text { innovative HWls of individual organizations in many provinces } \\
\text { and territories. }\end{array}$ \\
\hline $\begin{array}{l}\text { 6. Toward 2020: a proposal to strengthen Canada's } \\
\text { health human resources (Canadian Nurses } \\
\text { Association) }\end{array}$ & $\begin{array}{l}\text { The project has been completed, and the final report was } \\
\text { published (Villeneuve and MacDonald 2006). }\end{array}$ \\
\hline $\begin{array}{l}\text { 7. Understanding the costs and outcomes of nurses' } \\
\text { turnover in Canadian hospitals (Nursing Health } \\
\text { Services Research Unit, Faculty of Nursing, } \\
\text { University of Toronto) }\end{array}$ & $\begin{array}{l}\text { Work is in progress to study the effects of turnover on nurse } \\
\text { and patient outcomes; simulations are being performed to } \\
\text { estimate the effect of management interventions on system } \\
\text { outcomes. }\end{array}$ \\
\hline $\begin{array}{l}\text { 8. Quality Worklife-Quality Healthcare Collaborative: } \\
\text { linking quality of work life, human resource } \\
\text { practices and health system results (Canadian } \\
\text { Council on Health Services Accreditation) }\end{array}$ & $\begin{array}{l}\text { Work is in progress to develop a steering committee and } \\
\text { working groups, and to create a virtual clearinghouse for } \\
\text { innovative human resource practices. }\end{array}$ \\
\hline $\begin{array}{l}\text { 9. Health human resource strategy - Yukon projects } \\
\text { (2004-2005 to 2005-2006) (Department of Health } \\
\text { and Social Services, Government of Yukon) }\end{array}$ & $\begin{array}{l}\text { Project } 1 \text { is the Nursing Mentorship Feasibility Study. Project } 2 \\
\text { is the Healthy Workplace Indicators Study. }\end{array}$ \\
\hline
\end{tabular}

*Nursing Sector Study Corporation. 2005. Building the Future: An Integrated Strategy for Nursing Human Resources in Canada. Phase II Final Report Ottawa, Ontario: Author.

\section{Federal, Provincial and Territorial HHR Action Plans}

As part of the commitments made to reform the health workforce, Canada's federal, provincial and territorial governments agreed to report to the public on their action plans by December 31, 2005, including targets for training, recruitment and retention and healthy workplaces for health professionals.

To date, only Saskatchewan, Ontario, Quebec, Nova Scotia, New Brunswick,
Prince Edward Island, Newfoundland and Labrador, Nunavut and the Northwest Territories have released their action plans (Government of New Brunswick 2005; Northwest Territories Health and Social Services 2005; Ontario Ministry of Health and Long-Term Care [MOHLTC] and Ministry of Training, Colleges and Universities 2005; Santé et Services sociaux Québec 2004; Saskatchewan Health 2005). British Columbia, Alberta, Manitoba, the 
Table 2. Summary of healthy workplace targets and initiatives listed in provincial and territorial health human resources plans

\begin{tabular}{|c|c|}
\hline Jurisdiction & Healthy Workplace Targets and Initiatives \\
\hline Ontario & $\begin{array}{l}\text { No numerical targets for healthy workplaces are included. Key initiatives are as follows: } \\
\text { - Nursing Mentorship/Preceptorship Initiative } \\
\text { - New Graduate Initiative } \\
\text { - Nursing Education Initiative } \\
\text { - Late Career Initiative }\end{array}$ \\
\hline Nova Scotia & $\begin{array}{l}\text { No targets for healthy workplaces are included in the action plan. Key initiatives include } \\
\text { a provincial nursing strategy for nurse education, recruitment, retention and workforce } \\
\text { renewal. Since 2002, Nova Scotia has achieved its target of retaining at least } 80 \% \text { of its } \\
\text { new graduates. }\end{array}$ \\
\hline Saskatchewan & $\begin{array}{l}\text { Saskatchewan's action plan includes initiatives to increase recruitment and retention } \\
\text { by providing safe, supportive and quality workplaces that help to retain and recruit } \\
\text { healthcare professionals. While Saskatchewan's plan includes healthy workplace } \\
\text { objectives, it contains no specific numerical targets. Goals include the following: } \\
\text { - To decrease the number and severity of Workers' Compensation Board lost-time claims } \\
\text { - To increase the percentage of staff reporting a positive score for their learning } \\
\text { environment }\end{array}$ \\
\hline Quebec & $\begin{array}{l}\text { In the HHR section of Quebec's report, there are some important elements that attempt } \\
\text { to address workforce shortages, including changes to scopes of practices, recruitment of } \\
\text { internationally trained professionals and retention efforts for rural communities (Health } \\
\text { Council of Canada 2006). }\end{array}$ \\
\hline New Brunswick & $\begin{array}{l}\text { Key initiatives are as follows: } \\
\text { - The Annual/Provincial Bursary Program } \\
\text { - Continuing education, which includes a Clinical Education Program } \\
\text { - Conversion of casual positions to permanent positions } \\
\text { - Nursing Mentorship Program } \\
\text { - Phased Retirement Program } \\
\text { - Financial incentives } \\
\text { - Nursing education and training }\end{array}$ \\
\hline Prince Edward Island & $\begin{array}{l}\text { The plan includes activities and future strategies to try to address the challenges that } \\
\text { PEl experiences in recruiting and retaining healthcare professionals. No specific planned } \\
\text { activities were outlined to address workplace issues. }\end{array}$ \\
\hline Nunavut & $\begin{array}{l}\text { Nunavut's plan centres on the key challenge of recruiting and retaining health } \\
\text { professionals. The plan includes initiatives aimed at retention, increasing Aboriginal } \\
\text { participation in the workforce and developing leaders in the sector to act as mentors } \\
\text { and promote self-sufficiency (Health Council of Canada 2006). }\end{array}$ \\
\hline Northwest Territories & $\begin{array}{l}\text { The plan's primary focus is on getting people to work and remain in the territory. Future } \\
\text { efforts in the NWT include promoting healthcare to their population, promoting the } \\
\text { NWT as a place to live and work, improving succession planning and opportunities for } \\
\text { continuing professional development for employees and management and promoting } \\
\text { healthy workplaces. No numerical targets were identified in the plan. }\end{array}$ \\
\hline Newfoundland and Labrador & $\begin{array}{l}\text { The HHR action plan includes five goals. Goal four involves quality workplaces (to } \\
\text { participate in and support the healthy workplace initiatives focused on creating an } \\
\text { enhanced culture of safety and to continue to support the Quality Professional Practice } \\
\text { Environments for Nurses Initiative). No numerical targets were identified in the plan. }\end{array}$ \\
\hline
\end{tabular}

HHR = health human resources. 
Yukon and the Government of Canada are expected to release their plans in the near future (Health Council of Canada 2006a). In Table 2, we review the HHR plans that have been released to date to examine the extent to which those plans incorporate healthy workplace issues, initiatives and targets.

Our review of the policy progress demonstrates that federal, provincial and territorial governments and other stakeholder organizations are currently undertaking many healthy workplace initiatives across the nation. Our synthesis suggests that some are making significant commitments for healthy workplaces, particularly recruitment and retention initiatives. While many of those initiatives are focusing on financial incentives, such as tuition reimbursement, bursaries, loans, education opportunities and others, there is little evaluation of the impact of those incentives on improving the workplaces. Besides, literature argues that financial incentives are only one factor in creating healthier workplaces. For instance, the Health Council of Canada (2005) recommended that governments and other groups should develop non-financial recruitment and retention incentives. This recommendation was repeated in the recent council report (2006b) but with targets for employers to achieve by 2008 .

\section{Progress in Practice}

Our review demonstrates that there have been significant policy-level improvements, particularly in bringing the healthy workplace issues into the policy agenda of governments. Despite such improvements, many questions remain unanswered. For instance, have the existing policy initiatives resulted in healthier workplaces for healthcare workers? Simply put, are there indications that healthcare workers, particularly at the front line, are experiencing better working conditions? Examining those questions would help inform the debate about how to increase the chances that policy initiatives will bring effective changes to the workplaces and, hence, translate into a greater quality of patient care.

The CNAC's final report in 2002 was widely viewed as an essential document for those struggling with the complexity of nursing resource issues (CHSRF 2006). It gave stakeholders 51 ways to address the crisis. A subsequent study outlining which recommendations had been implemented revealed that progress has been slow and appears to be made in pockets (Canadian Policy Research Networks [CPRN] 2004). The findings of the progress report showed that there has been an increase in the number of education seats for $\mathrm{RNs}$, licensed practical nurses (LPNs) and registered practical nurses (RPNs). However, progress has not been widespread around issues pertaining to workload, the number of full-time equivalents (FTEs), absenteeism, nurse mentors and scheduling, and the changes have been concentrated in acute care facilities rather than community, long-term care or other settings. The report states that there are some recommendations that have been implemented in every jurisdiction across Canada but that some barriers remain, such as accountability issues in terms of implementation, resources for employers for workplace improvements and collective bargaining. While the report found positive signs of improvement in quality of nursing work life as recommended in the CNAC report, such changes are not widespread.

Over the past two to three years, several Canadian studies (both academic and grey literature) documented the progress made at the practice level in terms of healthy workplaces (mostly nursing literature). The most recent one is the research project 
Nursing Environments: Knowledge to Action (NEKTA), which identified positive changes in the nursing work environment (Leiter 2006). Below, we document evidence of the progress related to several thematic areas.

\section{Public Reporting on Healthy Workplaces for the Health Workforce in Hospitals} The hospital report on acute care prepared by the Canadian Institute for Health Information (2005; Howe et al. 2005; Wagg et al. 2006) included healthy work environment as an indicator within the quadrant of system integration and change. The healthy work environment indicator was measured using four components: (1) health workplace plan or policy, (2) accountability, (3) assessment and improvement and (4) key dimensions that include a healthy and safe physical environment, a positive psychosocial environment and an environment that promotes a healthy lifestyle (Howe et al. 2005).

According to the 2005 report, the provincial average performance of Ontario hospitals on the healthy work environment was $61.5 \%$, and there were significant variations between hospitals. Teaching hospitals had the highest average score at $67.9 \%$, community hospitals averaged $66 \%$ and small hospitals had an average score of $46.1 \%$. These scores represent data collected from 98 of the 108 hospitals that completed the system integration and change survey (Canadian Institute for Health Information 2005).

\section{Hospital Accountability Agreements}

The MOHLTC in Ontario has recently included healthy work environment as a measure in the Hospital Accountability Agreement. The target set by the ministry is the provision of at least $70 \%$ of front-line nursing by full-time nursing staff ( $\mathrm{RN}$ s and RPNs) (Ontario Joint Policy and Planning Committee 2005).

\section{Strategic Plans of Health Authorities} The NEKTA research project found evidence of healthy workplace objectives in the strategic plans of several district health authorities in the Atlantic region. For example, Leiter (2006) found that healthy workplace objectives are included in Strategic Plan 2002-2006 Annapolis Valley Health (Nova Scotia), Strategic Plan 2002-2006 Capital Health (Nova Scotia), Strategic Plan 2001-2005 IWK Health Centre (Nova Scotia), Strategic Plan 2003-2006 Atlantic Health Sciences Corporation (New Brunswick), Strategic Plan 2001-2005 Department of Health and Community Services (Prince Edward Island) and Strategic Plan 2004-2006 Eastern Health District (Newfoundland and Labrador).

\section{Physician Health and Well-Being}

The impact of a healthy workplace extends to physicians as well as nurses and other health workers. Physicians are just as vulnerable to the influence of stress in the workplace and challenges of balancing life and work. This was recognized by the Canadian Medical Association (CMA) in the policy passed in 1998 regarding physician health and well-being, which consequently led to the passing of three resolutions to support physician health in 2002 (CMA 2006). In 2003, the CMA launched the CMA Centre for Physician Health and Well-Being to be an information resource for physicians, medical students and their families, to help them maintain health and prevent illness and to provide national leadership and advocacy. In 2003, the centre also announced $\$ 100,000$ for research into doctors' health (Puddester 2004).

\section{Accreditation}

The framework of the Canadian Council on Health Services Accreditation (CCHSA) 
includes work life as one of its four quality dimensions. The work-life descriptors include open communication, role clarity, participation in decision making, learning environment and well-being. In addition, there are new healthy workplace indicators that have been developed by the CCHSA and are now being tested. These indicators will become part of the standards used to assess accreditation of healthcare settings across Canada. This will motivate employers to address working conditions and their impacts on employees and patients.

\section{Occupational Health and Safety}

The most common policy and regulation changes across provinces were related to the need for safer equipment (e.g., lifts and electric beds), musculoskeletal injury-prevention programs, return-to-work programs and violence-prevention programs. With the implementation of these programs, many provinces reported an initial drop in injury rates (Occupational Health and Safety Agency for Healthcare in BC [OHSAH] 2004). According to a report prepared by OHSAH and published by Health Canada (2004-2005), the national rates for time-lost injuries (all provinces combined) actually decreased from approximately 4.1 injuries per 100 FTEs in 1996 to 3.7 injuries per 100 FTEs in 2002. The report suggests that the many interventions and policy changes implemented throughout Canada have been at least partially effective in reducing the national injury rates in healthcare (OHSAH 2004).

In an effort to limit the incidence of needle-stick injuries and exposure to blood and body fluids, British Columbia, Alberta and Manitoba have amended their regulations to incorporate requirements for the use of safety-engineered devices (Visser
2006). British Columbia and Ontario have purchased new hospital beds and patient lifts designed to prevent back injuries among hospital and nursing home staff. For instance, Ontario has so far provided funding for more than 13,000 bed lifts in hospitals, long-term care homes and rehabilitation centres to help prevent injuries (Ontario MOHLTC and Ministry of Training, Colleges and Universities 2005). In 2004-2005, Ontario provided funding to help hospitals convert to safer medical equipment, including safety-engineered sharps devices. The OHSAH report found that Ontario's low frequency of time-lost injury claims in comparison to its large workforce is positive, and may indicate that health-related policies and programs implemented in this province have been successful. It appears that the injury rate in British Columbia had an important effect on the national rate as well, given that the dramatic decrease in its injury rate from 1999 to 2002 was also reflected in the decrease in the national injury rate. The positive results in British Columbia may be attributed to several reasons, ranging from the introduction of regulations for musculoskeletal injuries in 1997, to the formation of OHSAH, a provincial health and safety agency, in 1998, to the amalgamations of authorities in 2001 (OHSAH 2004).

\section{Health, Safety and Violence}

Site-specific safety programs are common (CHSRF 2006). For example, St. Michael's Hospital in Toronto is creating a healthy workplace scorecard that includes both mental and physical exposures to workplace hazards. Zero-tolerance and harassment policies are common in acute care settings (CHSRF 2006). 


\section{Education}

There has been an increase in the number of nursing seats (CPRN 2004). In 2001, education seats for RNs, LPNs and registered psychiatric nurses increased by 43\% compared with 1998 levels. British Columbia, Saskatchewan and Nova Scotia recently reported an even greater increase in seats. Many nursing schools are offering distance education programs; for example, in Newfoundland and Labrador, distance technology is used for the bachelor, graduate and postgraduate programs, as well as for continuing education. Also, British Columbia, Alberta, New Brunswick, Prince Edward Island and Newfoundland and Labrador have established paid co-operative placement programs for upper-year RN students, which provide students with income and work experience (CHSRF 2006). The Reimbursement of Tuition for Refresher Program issued in New Brunswick in 2001 encouraged RNs and LPNs to re-enter the nursing profession, and provided the province with a pool of skilled health professionals who had been out of the workforce. Ontario has provided funding for all schools of nursing to purchase clinical simulation equipment in order to ensure that nursing students are confident in their knowledge and skills, making them more practice ready upon graduation.

\section{Professional Development, Continuing Education and Training}

Many jurisdictions have instituted supportive education programs. For example, they fund education and professional development programs for RNs, LPNs and registered psychiatric nurses (Health Council of Canada 2005). New Brunswick, for instance, developed a continuing education initiative that includes Clinical Education
Program funding to promote continuing education events for health professionals. Another example is the Skills Enhancement for Health Surveillance Program, which is a continuing education initiative of the Public Health Agency of Canada for frontline public health professionals (Health Council of Canada 2005). In addition, healthcare organizations have started to institute continuing education programs. For example, the Hospital for Sick Children pays for nurses to attend conferences and provides a nursing scholarship program and a research training competition to support graduate education (CHSRF 2006). In its HHR action plan, Ontario outlined that it will provide funding to support professional development activities for practising nurses. In Nova Scotia, the nursing strategy offers programs to support employers in their recruitment and retention efforts, including funding for orientation, continuing education, bursaries, co-operative education programs, re-entry, relocation, recruitment websites and job fairs, nursing grants and leadership development (Nova Scotia Health 2005). Beginning in 2003, Nova Scotia committed funding to train 60 additional nurses each year for a four-year period.

\section{Staffing}

Some jurisdictions, such as Ontario, created new full-time positions for new nurse graduates; others, such as New Brunswick, have converted casual positions to permanent, aiming to improve staffing levels and mix and to decrease the workload. In 2004-2005, Ontario provided 1,000 temporary full-time positions for new nursing graduates to help them make a successful transition to the workforce. In New Brunswick, from 1999 to 2004 , the number of permanent RNs increased to 6,726 from 6,014 , or by $11.8 \%$, 
while the number of permanent LPNs increased to 1,934 from 1,634, an increase of more than $18 \%$. By 2004 , only $6.7 \%$ of nurses employed in New Brunswick were working as casuals (Government of New Brunswick 2005). In Nova Scotia, 238 more LPNs and RNs were employed in 2004 than in 2002 (Nova Scotia Health 2005).

\section{Workload}

In their HHR action plans, reported jurisdictions did not include any numerical targets for workload. Based on a review of several documents, a recent report stated that workload measurement systems are in place in the acute care sector across the country (CHSRF 2006). However, there is no evidence yet on whether the actual workload for healthcare workers has eased. In this recent report, it was noted that nursing unions in at least five provinces are bringing workload issues into contract negotiations. A similar observation was noted in the recent NEKTA report, which found that nurses' workload has not been eased in the Atlantic provinces (Leiter 2006).

\section{Retention of Older Workers}

The most notable accomplishment in retention of older workers is New Brunswick's phased-in retirement program. In New Brunswick, union contracts allow for phased-in retirement and also give full benefits for part-time and casual nurses. At age 55 years, nurses can opt for parttime work, keep their benefits and begin to collect a pension. This has the double benefit of opening up places for new graduates while retaining the skills and mentorship of experienced nurses (Health Council of Canada 2005). Three other provinces plan to introduce similar measures during collective bargaining (CHSRF 2006).

\section{Flexible Scheduling}

According to a recent report (CHSRF 2006), it was stated that some collective agreements contain arrangements for selfscheduling, flexible scheduling, job sharing or other work options. For instance, New Brunswick negotiated a new four-year collective agreement for RNs, nurse managers and nurse supervisors offering salaries and working conditions that are competitive with the other Atlantic provinces. Also, the phased retirement program in $\mathrm{New}$ Brunswick offers nurses the opportunity to work part time rather than leave their jobs completely. The NEKTA report found evidence of progress in the area of selfscheduling in Atlantic Canada (Leiter 2006).

\section{Best Practice Guidelines for Workplace Health}

The Healthy Work Environments Best Practice Guidelines project was designed to support healthcare organizations in creating and sustaining positive environments for nurses. Led by the Registered Nurses' Association of Ontario (RNAO) and funded by the Ontario MOHLTC working in partnership with Health Canada, Office of Nursing Policy, this project will deliver six guidelines and systematic literature reviews related to healthy work environments. The first, "Developing and Sustaining Nursing Leadership," was released in June 2006 after extensive consultation and review by panels and an advisory board containing Canadian and international experts (RNAO 2006).

\section{Innovative Opportunities for Healthcare Workers to Take on New Roles}

When experienced healthcare providers move from full-time practice into mentoring new graduates, a significant investment in time is required (Health Council of Canada 2005). Innovations have been introduced 
to address these issues. For example, in Alberta's Capital Health region, hiring a new nursing graduate creates an additional position for the first year, over and above the current staffing allocation. The program is designed to improve job satisfaction for older nurses and increase retention of new nurses (Health Council of Canada 2005). The Montreal Regional Health Authority has undertaken a similar program to support newly qualified nurses.

Another innovative initiative is the 8020 model, where front-line nurses have $20 \%$ of their clinical time freed from their regular working day to focus on teaching, research or on-the-job mentoring. In Ontario, the 80-20 model is being introduced provincewide as an option for nurses aged 55 years and older, as part of efforts to reduce early retirement (Health Council of Canada 2005). In 2004-2005, Ontario established nurse mentorship programs in 45 healthcare organizations across the province and provided funds to support late-career nurses in less physically demanding roles (Ontario MOHLTC and Ministry of Training, Colleges and Universities 2005).

Despite all the initiatives that are currently under way to improve workplaces, there still are few indications that healthcare workers, particularly at the front line, are experiencing better working conditions. This does not mean that the initiatives are not effective - progress at the practice level takes time. More evaluation research is needed to document the effects of those initiatives on the front-line workers. A recent review prepared by CHSRF showed that there are few indications that frontline nurses are experiencing better working conditions (CHSRF 2006). In hospital wards and units, in long-term care facilities and in the community, front-line nurses continue to work overtime, are injured or ill, lack leadership and support and become discouraged, stressed and burnt out. Another recent study found that the nursing practice environment for Ontario acute care hospitals continues to be rated poorly by medical nurses (Tourangeau et al. 2006).

\section{Next Steps for Research, Policy and Practice}

While there has been significant progress in bringing policy changes as a result of research evidence, our synthesis suggests that more work is needed to ensure that existing policy initiatives bring effective changes to the workplace. After all, the ultimate objectives of the healthy workplace agenda are to ascertain that healthcare workers, particularly at the front line, are experiencing better working conditions. This will translate into better quality of care, organizational performance and system outcomes.

While we recognize that progress at the practice level takes time, there are still few indications that healthcare workers are working in good practice environments. In 2003, over 13,000 Ontario nurses were surveyed to explore how they evaluated their hospital work environments and their responses to these practice environments. Nurses reported weak professional practice environments, weak job satisfaction and moderate levels of burnout (Tourangeau et al. 2005). Although it should be kept in mind that most policy initiatives started in 2005, we believe that important next steps are required to bring effective and much faster and sustainable changes to the practice environments. Below we outline the next steps for research, policy and practice that are required to help the healthy workplace agenda achieve its ultimate objectives.

\section{Next Steps for Research}

Next steps to be taken in research to achieve 
healthy workplace objectives are as follows:

- Evaluation research is needed to provide indications that the front-line healthcare workers are experiencing better working conditions. If healthcare organizations are to track whether healthy workplace initiatives are achieving their desired effects, some evaluation of the implementation is needed in research. Yet, there have been few evaluations done of the impact of such initiatives (El-Jardali and Fooks 2005).

- More research is needed to provide an update on the state of implementation of CNAC recommendations and to facilitate further implementation (CPRN 2004).

- Learning is required from micro-level innovations at the practice environment level. Monitoring, evaluation, documentation and effective dissemination and exchange mechanisms are essential.

- Greater sharing of knowledge is needed about what works with respect to workplace practice issues where, not surprisingly, most of the research and innovation comes from nursing. Research is needed to translate innovations from one profession to others, particularly to translate innovations in nursing workplace practices to other types of healthcare (Health Council of Canada 2005).

- More knowledge is needed regarding the ease of implementing healthy workplace interventions, the costs involved and time frames for the effects to take place.

- Working conditions have been researched in acute care settings, but for long-term care and home care settings, almost nothing is known. With the increasing shift to community-based care, research is needed to increase the knowledge on how to best recruit and retain healthcare workers in home and community care settings (Victorian Order of Nurses 2005).

- Implementation and evaluation of outcomes and impacts of RNAO healthy work environment guidelines are needed, particularly their impact on patient, nurse and system outcomes. And more systematic research is needed on the impact of healthy workplaces on societal outcomes.

- Research should continue to change the way of thinking about healthy workplaces, particularly to improve the understanding of the benefits of healthy workplaces that matter to the policy-makers and employers. In order to promote and keep healthy workplace issues in political agendas, researchers need to use innovative and effective dissemination strategies to make better instrumental and strategic use of their research evidence.

- More public reporting of measurable results from healthy workplace initiatives is encouraged - both to increase transparency and accountability and to share information on successes and barriers.

- Continued examination of work-life indicators within the accreditation processes is required to determine whether the health of the workplace and its link to patient outcomes is adequately measured. The CCHSA should further develop indicators for healthy workplaces to be integrated in accreditation standards and balanced scorecard reports.

- Comparable indicators on workplace health are required in order to make comprehensive assessments in areas such as retention, satisfaction and other aspects of healthy workplaces. 


\section{Next Steps for Policy}

Next steps to be taken in policy to achieve healthy workplaces include the following:

- There needs to be a better integration of healthy workplace indicators and numerical targets within the HHR strategies and action plans of federal, provincial and territorial governments.

- Accountability frameworks that include healthy workplace indicators should be introduced. For example, healthy workplace indicators should be integrated within the performance agreements between governments and employers.

- Governments and stakeholders should support employers in implementing action plans to meet the healthy workplace targets for 2008 developed by the Health Council of Canada.

- The Health Council of Canada should ensure that recommendations and targets for healthy workplaces are implemented. The council plans to report publicly on interim progress toward achieving healthy workplace targets for 2008 (Health Council of Canada 2005).

- Governments need to evaluate the implementation of their healthy workplace initiatives to ensure good outcomes and sustain the momentum for positive change.

- Sustainability of funding healthy workplace initiatives that are targeted at the organizational level (i.e., front line) needs to be ensured.

- New collective agreements should contain arrangements for self-scheduling, flexible scheduling, overtime, job sharing and other setups.

- Policy consensus is needed on strategies and incentives (i.e., non-financial) to improve practice environments for healthcare workers.
- The Quality Worklife-Quality Healthcare Collaborative (CCHSA) must act both as a knowledge-transfer laboratory and a best practice clearinghouse for healthy workplace information. There should be a call for a greater sharing of knowledge about what works in healthy workplace practices, where most of the research and innovation comes from nursing (Health Council of Canada 2005). The collaborative can create more opportunities to translate innovations in nursing workplace practices to other types of care providers.

\section{Next Steps for Practice}

Finally, next steps to be taken in practice to achieve healthy workplace objectives are as follows:

- The healthy workplace targets for 2008 developed by the Health Council of Canada (Health Council of Canada 2005) need to be implemented.

- The notion of "professional development to lifelong learning" should be broadened in an effort to make it more inclusive (WHO 2006). Employers need to make professional development a regular part of budget planning and provide time for staff to enhance their training.

- Whether current collective agreements might be a barrier or facilitator to creating quality practice environments for healthcare professionals should be explored.

- There needs to be an improvement in management and leadership, such as more on-the-job leadership training. The goal is to help supervisors and middle managers do a better job of managing the tension between productivity and workers' health and safety.

- Employers must practise ethics-based 
leadership (Morrison 2006) - people expect healthcare organizations to act with social responsibility and serve as good stewards of resources to make every effort to provide good working conditions for health workers, which translates into greater quality of care.

- Different styles of management and leadership are recommended for implementing healthy workplace initiatives. Johnson et al. (2003) stress that the current workplace health situation is still managed through conventional management practices and is shaped according to the practices of employment law.

- We must act now to cut waste and improve incentives. This can be achieved by reducing absenteeism and turnover and improving performance through compensation adjustment, work incentives and safe working conditions (WHO 2006).

- Healthcare organizations should develop a statement of clear vision and values that reflects the importance of supporting healthy workplaces. Employers should demonstrate that employee health and well-being are an integral part of their strategic plans (i.e., the way they do business). Healthy workplace indicators and numerical targets should be included in their strategic plans.

- Employers need to monitor and evaluate the implementation and impact of healthy workplace initiatives on the front-line healthcare workers.

- Healthy Work Environments Best Practice Guidelines established by the RNAO should be used as tools for the development and sustainability of a healthy work environment. The extensive work and consultation undertaken in this project allowed for the development of a comprehensive and valuable set of guidelines to which workplaces should adhere.

\section{Summary}

The progress in the healthy workplaces for health workers agenda in Canada is a classic example of how knowledge can be used for policy and practice. It further evidences the need for collaboration between researchers, policy-makers, decision makers, stakeholders and practitioners. There have been major accomplishments to date, but change takes time and it is important to continue the efforts at all levels until we attain healthy workplaces by all measures.

\section{References}

Addley, K., P. McQuillan and M. Ruddle. 2001. "Creating Healthy Workplaces in Northern Ireland: Evaluation of a Lifestyle and Physical Activity Assessment Programme." Journal of Occupational Medicine 51: 439-49.

Bachmann, K. 2000. More than Just Hard Hats and Safety Boots: Creating Healthier Work Environments. Ottawa: The Conference Board of Canada.

Canadian Health Services Research Foundation. 2001. "Commitment and Care: The Benefits of a Healthy Workplace for Nurses, Their Patients, and the System." Healthcare Papers 2(1): 10-29.

Canadian Health Services Research Foundation. 2006. What's Ailing Our Nurses? A Discussion of the Major Issues Affecting Nursing Human Resources in Canada. Ottawa: Author.

Canadian Institute for Health Information, Government of Ontario, Ontario Hospital Association and the University of Toronto. 2005. Hospital Report 2005: Acute Care. Ottawa: Canadian Institute for Health Information. <http://www. oha.com/Client/OHA/OHA_LP4W_LND_ WebStation.nsf/resources/Hospital+Reports/\$file/ OHARep2005_EN.pdf>. Last accessed April 11, 2006.

Canadian Medical Association. 2006. CMA Centre for Physician Health and Well-Being. Ottawa: Author. Retrieved July 26, 2006. <http://www.cma.ca/index. cfm/ci_id/25544/1a_id/1.htm>.

Canadian Nursing Advisory Committee. 2002. Our Health, Our Future: Creating Quality Workplaces for Canadian Nurses. Ottawa: Author. Retrieved August 
15, 2005. <http://www.hc-sc.gc.ca/hcs-sss/pubs/caresoins/2002-cnac-cccsi-final/index_e.html>.

Canadian Policy Research Networks. 2004.

Improving Work Life for Nurses: Some Progress, but Much to Be Done. Ottawa: Author.

Chu, C., G. Breucker, H. Harris and A. Stitzel. 2000. "Health-Promoting Workplaces - International Settings Development." Health Promotion

International 15(2): 155-95.

Commission on the Future of Health Care in Canada. 2002. Building on Values: The Future of Health Care in Canada. Canada: Author. Available on: www. cbc.ca/healthcare/final_report.pdf. Last accessed April 28, 2006.

Dejoy, D.M. and D.J. Southern. 1993. "An Integrative Perspective on Work-Site Health Promotion." Journal of Occupational Medicine 35(12): 1221-30.

Dejoy, D.M. and M.G. Wilson. 2003.

"Organizational Health Promotion: Broadening the Horizon of Workplace Health Promotion." American Journal of Health Promotion 17(5): 337-41.

Duxbury, L., C. Higgins and K.L. Johnson. 1999. An Examination of the Implications and Costs of Work-Life Conflict in Canada. Ottawa: Health Canada.

El-Jardali, F. and C. Fooks. 2005. An Environmental Scan of Current Views on Health Human Resources in Canada: Identified Problems, Proposed Solutions and Gap Analysis. Toronto: Health Council of Canada.

Ennals, R. 2002. "Partnerships for Sustainable Healthy Workplaces." The Annals of Occupational Hygiene 46(6): 423-28.

Government of New Brunswick. 2005. Health

Human Resource Planning: Gaining Momentum. New Brunswick: Author.

Griffin, P., F. El-Jardali, D. Tucker, D. Grinspun, I. Bajnok and J. Shamian 2006. "What's the Fuss About? Why Do We Need Healthy Work Environments for Nurses Anyway?" HHResources.ca $<$ http://www.longwoods.com/home.php?cat=110>.

Health Canada. 2003. First Ministers' Accord on Health Care Renewal. <http://www.hc-sc.gc.ca/hcssss/delivery-prestation/fptcollab/2003accord/index_ e.html>.

Health Canada. 2004-2005. Pan-Canadian Health Human Resource Strategy Annual Report. Ottawa: Author.

Health Council of Canada. 2005. Modernizing the Management of Health Human Resources in Canada. Toronto: Author.
Health Council of Canada. 2006a. Progress Update: Wait Time and Health Human Resources - A Supplement to Health Care Renewal in Canada. Toronto: Author.

Health Council of Canada. 2006b. Health Care Renewal in Canada: Clearing the Road to Quality. Toronto: Author.

Howe, N., J. Wagg, N. Seeman and R. Baker. 2005. Hospital Report 2005: Acute Care, System Integration and Change Technical Summary. Ottawa: Canadian Institute for Health Information, Government of Ontario, Ontario Hospital Association and the University of Toronto. <http://www.hospitalreport. ca/downloads/2005/AC/AC_SIC_TechReport_ FINAL.pdf>. Last accessed April 3, 2006.

Johnson, C.J., E. Croghan and J. Crawford. 2003. "The Problem and Management of Sickness Absence in the NHS: Considerations for Nurse Managers." Journal of Nursing Management 11: 336-42.

Jones, M.C. and D.W. Johnston. 2000. "A Critical Review of the Relationship between Perception of the Work Environment, Coping and Mental Health in Trained Nurses, and Patient Outcomes." Clinical Effectiveness in Nursing 4: 75-85.

Kelloway, E.K. and A.L. Day. 2005. "Building Healthy Workplaces: What We Know so Far." Canadian Journal of Behavioural Sciences 37(4): 223-35.

Khoury, G., J. Rostami and P.L. Turnbull. 1999. Corporate Social Responsibility: Turning Words into Action, Members'Briefing 255-99. Ottawa: The Conference Board of Canada.

Kramer, D.M. and D.C. Cole. 2003. "Sustained, Intensive Engagement to Promote Health and Safety Knowledge Transfer to and Utilization by Workplaces." Science Communication 25(1): 56-82.

Laschinger, H. and M. Kerr. 2004. Conceptual Model for Monitoring the Health of Nurses. Toronto: Institute for Work and Health. Retrieved December 1, 2004. $<$ http://www.iwh.on.ca/products/atwork2002/dec_ 2002/nurses.htm>.

Lee, J.L., B.L. Chang, M.L. Pearson, K.L. Kahn and L.V. Rubenstein. 1999. "Does What Nurses Do Affect Clinical Outcomes for Hospitalized Patients? A Review of the Literature." Health Services Research 34(5): 1011-32.

Leiter, M.P. 2006. Nursing Environments: Knowledge to Action. Ottawa: Health Canada.

Lowe, G. 2003. Healthy Workplaces and Productivity: A Discussion Paper. Ottawa: Health Canada. <http:// www.cprn.org/en/doc.cfm?doc=300>. Last accessed April 14, 2006. 
Morrison, E.E. 2006. Ethics in Health Administration: A Practical Approach for Decision Makers. London, England: Jones and Bartlett Publishers International.

Needleman, J., P. Buerhaus and M. Stewart. 2001. Nurse Staffing and Patient Outcomes in Hospitals. Boston: Harvard School of Public Health.

Northwest Territories Health and Social Services. 2005. Status Report on the Human Resource Strategy Action Plan. Yellowknife: Author.

Nova Scotia Health. 2005. Health Human Resources Action Plan, Nursing Human Resources in Canada. Halifax: Author. <www.gov.ns.ca/health/downloads/hhr\%20action\%20plan-full\%20book.pdf $>$. Last accessed April 14, 2006.

O'Brien-Pallas, L. and A. Baumann. 1992. "Quality of Nursing Worklife Issues. A Unifying Framework." Canadian Journal of Nursing Administration 5(2): 12-16.

Occupational Health and Safety Agency for Healthcare in BC. 2004. Trends in Workplace Injuries, and Policies in Healthcare across Canada. Ottawa: Office of Nursing Policy, Health Canada.

Ontario Joint Policy and Planning Committee. 2005. A Primer on Performance Indicators and Standards for Use in 2005/06 and 2006/07. Toronto: Author.

Ontario Ministry of Health and Long-Term Care and Ministry of Training, Colleges and Universities. 2005. Laying the Foundation for Change: A Progress Report on Ontario's Health Human Resources Initiatives. Toronto: Author. <www.health.gov. on.ca/english/public/pub/ministry_reports/hhr_05/ hhr_05.pdf>. Last accessed April 28, 2006.

Price, J.L. and C.W. Mueller. 1981. Professional Turnover: The Case of Nurses. New York: SP Medical and Scientific Books.

Puddester, D.G. 2004. "Canada Responds: An Explosion in Doctors' Health Awareness, Promotion and Intervention." The Medical Journal of Australia 181(7): 386-87.

Registered Nurses' Association of Ontario. 2006. Healthy Work Environments Best Practice Guidelines. Toronto: Author. <http://www.rnao.org/ Storage/16/1067_BPG_Sustain_Leadership.pdf>. Last accessed April 3, 2006.

Santé et Services sociaux Québec. 2004. Report on the Progress Made Regarding the Bilateral Agreement Entered into during the Federal-Provincial-Territorial Meeting of the First Ministers on Health. Quebec: Author. <http://publications.msss.gouv.qc.ca/acrobat/f/documentation/2005/05-720-01A >. Last accessed April 16, 2006.
Saskatchewan Health. 2005. Working Together: Saskatchewan's Health Workforce Action Plan. Regina: Author. <www.health.gov.sk.ca/hplan_health_workforce_action_plan.pdf $>$. Last accessed April 3, 2006.

Schaefer, J.A. and R.H. Moos. 1993. "Work Stressors in Health Care: Context and Outcomes." Journal of Community and Applied Social Psychology 3(4): 235-42.

Sexton, J.B., E.J. Thomas and R.L. Helmreich. 2000. "Error, Stress, and Teamwork in Medicine and Aviation: Cross-Sectional Surveys." British Medical Journal 320: 745-49.

Shain, M. 2000. "Visions of the Healthy Workplace: Reflections on the Role of Comprehensive Workplace Health Promotion." Overheads presented at "Towards a More Integrated Approach to Workplace Health," April 6, 2000, Toronto. Unpublished proceedings.

Shain, M. and D.M. Kramer. 2004. "Health Promotion in the Workplace: Framing the Concept; Reviewing the Evidence." Occupational and Environmental Medicine 61: 643-48.

Standing Senate Committee on Social Affairs, Science and Technology. 2002. The Health of Canadians - The Federal Role. Ottawa: Author.

Tourangeau, A.E., A.L. Coghlan, J. Shamian and S. Evans. 2005. "Registered Nurse and Registered Practical Nurse Evaluations of Their Hospital Practice Environments and Their Responses to These Environments." Canadian Journal of Nursing Leadership 18(4): 54-69.

Tourangeau, A., D. Doran, D. Pringle, L. O'BrienPallas, L. McGillis Hall, J.V. Tu and A. Verma. 2006. Nurse Staffing and Work Environments: Relationships with Hospital Level Outcomes - Final Report. Ottawa: Canadian Health Services Research Foundation.

Tyler, P. and D. Cushway. 1992. "Stress, Coping and Mental Wellbeing in Hospital Nurses." Stress Medicine 8(2): 91-98.

van Servellen, G. and M.A. Schultz. 1999.

"Demystifying the Influence of Hospital Characteristics on Inpatient Mortality Rates." Journal of Nursing Administration 29(4): 39-47.

Verow, P. and C. Hargreaves. 2000. "Healthy Workplace Indicators: Costing Reasons for Sickness Absence within the UK National Health Service.” Journal of Occupational Medicine 50: 251-57.

Victorian Order of Nurses. 2005. Issues Related to Healthy Workplaces and Recruitment and Retention of Home and Community Care Nurses: A Synthesis Paper. Ottawa: Author. 
Villeneuve, M. and J. MacDonald. 2006. Toward 2020: Visions for Nursing. Canadian Nurses Association. Ottawa, Ontario.

Visser, L. 2006. “Toronto Hospital Reduces Sharps Injuries by $80 \%$, Eliminates Blood Collection Injuries. A Case Study: Toronto East General Hospital Pioneers Healthcare Worker Safety." Healthcare Quarterly 9(1): 68-70.

Wagg, J., J. Tse, N. Seeman, R. Baker, V. Flintoft and J. Paul. 2006. Hospital Report 2006: Acute Care, System Integration and Change Technical Summary. Ottawa: Canadian Institute for Health Information,
Government of Ontario, Ontario Hospital Association and the University of Toronto. <http:// www.hospitalreport.ca/downloads/2006/AC/2006_ AC_sic_technotes.pdf >. Last accessed April 15, 2006.

Whitehead, D. 2006. "Workplace Health Promotion: The Role and Responsibility of Healthcare

Managers." Journal of Nursing Management 14: 59-68.

World Health Organization. 2006. Working Together for Health: The World Health Report 2006. Geneva: Author.

\title{
Sometimes words aren't enough to encourage evidence-informed decision-making.
}

\author{
The Canadian Health Services Research Foundation presents \\ a short documentary film about the benefits of teamwork \\ in healthcare, with an engaging cast of researchers, \\ policymakers, staff and patients.
}

Check out the documentary by journalists Ray Moynihan and Miranda Burne at www.chsrf.ca.

\section{CHSRF}

\section{$\overline{\text { FCRSS }}$}

Canadian Health Services Research Foundation

Fondation canadienne de la recherche sur les services de santé

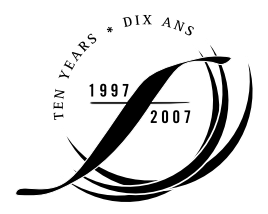

